accident, for which they were claiming compensation, whether they could see as well with the right eye as the left. Seven replied that they had noticed some impairment of vision in the right eye. On testing the field of vision with a finger, no narrowing was observed, and they explained that the deficiency they had spoken about was a blurring or general loss of clearness of vision. But when tested with a perimeter all of the seven showed a narrow field on the right side, and one had a slighter narrowing on the left side. In the only two cases in which it occurred to us to continue the investigation after the first field had been marked out a spiral was obtained (Fig. 5), which was identical in character with that supposed to be characteristic of hysteria.

1. P. Janet.-Etat Mental des Hystériques, 1911.

2. de Schweinitz in Posey and Spiller's The Eye and Nervous System, 1906, p. 625.

3. J. Babinski.-Semaine médicale, 1909, Vol. XXIX, p. 3.

4. Quoted by J. Babinski and J. Froment.-Hysterie-Pithiatisme, p. 66, Paris, 1917.

\title{
HEREDITARY GLIOMA OF THE RETINA
}

BY

H. M. TRAQUAIR, ASSISTANT OPHTHALMIC SURGEON, ROYAL INFIKMARY, EDINBURGH.

IN the Transactions of the Ophthalmological Society of the United Kingdom for 1917, two instances of families affected with hereditary glioma retinae are recorded by Mr. Hill Griffith, who suggests that, in view of their rarity, all such cases should be published.

The following case was recently seen in the clinic under the charge of Dr. J. V. Paterson, at the Edinburgh Royal Infirmary.

The father, A., when six months old, had his left eye removed by the late Argyll Robertson, "for a tumour." Unfortunately, no contemporary record is available, but there can be no doubt that the eye was removed on account of glioma.

A. was married in 1912. Family :

1. Still-birth, "six weeks overdue." 1913.

2. George. 1914. The parents noticed something wrong with the right eye when the child was six weeks old. At eight months, the eye was removed. In June, 1916, glioma of the left eye was apparent, and the orbit was exenterated in 1917. Metastases occurred all over the body, the head became horribly deformed and enlarged, and death supervened in 1918.

3. Mary. 1916. Parents noticed something in the left eye at six weeks. When the child was later brought to the hospital, glioma was diagnosed. Operation was refused and death occurred from broncho-pneumonia soon afterwards. 
The literature is given in Mr. Griffith's paper, though unfortunately some errors have crept into the references. The present case makes the eighth on record, and the third with transmission from the father. Owen's case is the earliest, the father's eye having been removed in 1859, the child's in 1898. The second case in chronological order is that of de Gouvêa, in which the father's eye was removed in 1872. Until recently the existence of hereditary glioma was doubted; its appearance has followed, and probably largely resulted from, advances in medical skill, such as the adoption of chloroform anaesthesia and the development of ophthalmoscopic diagnosis: measures which now often enable individuals to attain the age of reproduction, who would previously have died in childhood. It is, therefore, to be expected that these cases will be more numerous in future.

Writers on glioma are generally agreed that the beginning of the disease always, or at least very often, takes place in intrauterine life. In the present case, and in both of Mr. Griffith's families, still-births occurred. It would be of great interest if it could be ascertained whether still-births are relatively more numerous in gliomatous families and what is the exact cause of foetal death in such cases.

My thanks are due to Dr. J. V. Paterson for kindly permitting the publication of this case.

\section{COUNCIL OF BRITISH OPHTHALMOLOGISTS}

\section{Report on Standard Illumination of Snellen's Distant Test Types}

THE Council of British Ophthalmologists appointed a committee in July, 1918, to determine a standard of illumination of Snellen's test types of distant vision. The Committee consisted of the following members: Sir George Berry (Chairman), Sir Richard Glazebrook, C.B., F.R.S. (Director, National Physical Laboratory), Mr. Leon Gaster (Society of Illuminating Engineers), Mr. J. Herbert Fisher, Col. J. Herbert Parsons, Mr. A. B. Cridland, Mr. C. C. Paterson, O.B.E., and Mr. W. H. McMullen, O.B.E. (Secretary). The unanimous report of this committee was, after full consideration and discussion, adopted and is now issued by the Council.

\section{Report of Committee on the Illumination of Snellen's Distant Test Types}

The effect upon visual acuity of variations in the illumination of test objects has been the subject of a series of careful investigations 